\title{
Determination of GMO Soy Products in Processed Food from Bosnian and Herzegovinian Market
}

\author{
Amar Čosic ${ }^{1}$, Ajdina Karić², Kanita Šabanović ${ }^{3}$, Ahmet Yildirim ${ }^{4}$, Jasmin Šutkovićc $^{*}$ \\ $1,2,3,4,5$ Genetics and Bioengineering, International University of Sarajevo
}

\begin{tabular}{|c|c|}
\hline $\begin{array}{l}\text { (C) The Author } \\
2020 .\end{array}$ & Abstract \\
\hline $\begin{array}{l}\text { Published by } \\
\text { ARDA. }\end{array}$ & $\begin{array}{l}\text { The Bosnian and Herzegovinian market lacks data about the percentage of } \\
\text { genetically modified soy products placed on the domestic market. There has been } \\
\text { research on the issue of the presence of GMO products in our domestic market, } \\
\text { but neither of the results is used as a reference for this occurrence. Therefore, this } \\
\text { research topic tends to contribute to this issue, by examining genetically modified } \\
\text { soy in processed food. The sample of seven products containing soya is examined } \\
\text { by the methods of DNA isolation and real-time PCR for CP4 EPSPS. The results } \\
\text { showed positive results for the presence of CP4 gene in certain products without } \\
\text { an appropriate label. This mislabeling was confirmed since a couple of samples } \\
\text { were labeled as GMO-free but contained CP4 gene, indicating GMO product. }\end{array}$ \\
\hline
\end{tabular}

Keywords: GMO; soybean; food; lectin; CP4 gene

\section{Introduction}

\subsection{GMO and GMO legislation}

The usage of genetically modified organism (GMO) in recent years has increased drastically over few years. Definition of GMO's tend to vary between scientist, but according to NCBI MeSH, GMO are: "Organisms whose genome has been changed by a genetic engineering technique" [1]. Many food products found on today's markets are being sold as GMOs or are containing ingredients derived from GMO foods [2]. Over the years, European Union (EU) has imposed strict regulations on production and distribution of GMO foods. The legal framework seeks to protect human and animal health with high safety standards, provide efficient procedures to assess the risk of GMOs, ensure effective labelling of GMOs to help consumers make an informed decision, and finally, to provide traceability of market GMOs. EU rulebook says that a product which contain more than $0.9 \%$ of genetic modification requires special labelling procedure for GMO [3]. According to the agency for food safety in Bosnia and Hercegovina the GMO food has the same ruleset which was fixed by EU legislation [4].

\subsection{Soybean}

Soybean is plant that holds the biggest ratio of planted GMO's worldwide. $82 \%$ of the total Soybean is genetically modified [5]. It is grown everywhere and used as an important component of food formulations. Soya as a food is highly nutrient, and a great source of proteins, so wide amount of people can intake it. The uses of soy protein for example span from emulsification to provision of essential dietary amino acids [6].

\subsection{Roundup Ready ${ }^{\mathrm{TM}}$}

From GM crop species, soybean (Glycine max L.) is a major part of it, as soybean account for about $50 \%$ of the total planted areas with GMO. In 1996, the first crop to be approved to produce food was soybean Roundup Ready ( $\mathrm{RR}^{\mathrm{TM}}$ ), that was made by Monsanto. It is tolerant to Roundup herbicide [7].

The broad-spectrum herbicide glyphosate, which it the active ingredient of Roundup herbicide, is inhibiting 5enolpyruvylshikimate-3- phosphate (EPSP) synthase, which is an enzyme that catalyzes the penultimate step of the shikimate pathway, to the biosynthesis of aromatic amino acids. 
The $\mathrm{RR}^{\mathrm{TM}}$ contains a gene, which is derived from Agrobacterium sp. Strain CP4, which encodes a glyphosatetolerant enzyme. It is called CP4 EPSP synthase (EPSPS), which expression is resulting in crops that are glyphosate-tolerant, which enables to control the weed more efficiently. It is adopted in $87 \%$ of soybeans $[8,9]$.

\subsection{Aim of the study}

The purpose of this study is to examine the soy content of the selected food products across the Bosnian and Herzegovinian market and determine whether it is in accord with EU regulations.

\section{Materials and Methods}

\subsection{Soybean product samples}

Soya bean product were chosen from local supermarkets and shown in table 1 . The reason these were chosen is that for most of them it is said that are GMO free, as well as they all represent a healthy lifestyle product.

Table 1.

\begin{tabular}{ccc}
\hline Sample number & Sample & Label \\
\hline 1 & Soy flakes & $\mathrm{X}$ \\
2 & Breakfast cereal & $\mathrm{X}$ \\
3 & Soy meat 1 & GMO free \\
4 & Soy meat 2 & GMO free \\
5 & Soy flour & X \\
6 & Soy cream & GMO free \\
7 & Soy cappuccino & $\mathrm{X}$ \\
\hline
\end{tabular}

\subsection{DNA isolation, purity, and concentration}

DNA isolation was performed using optimized CTAB protocol. New optimized procedure was based on homogenization tissue in CTAB extraction buffer and selective precipitation of DNA with isopropanol. DNA concentration and purity were determined using Multiskan ${ }^{\mathrm{TM}}$ GO Microplate Spectrophotometer, Thermo Scientific and DNA integrity was confirmed by $1.5 \%$ agarose gel.

\subsection{Quantitative Polymerase Chain Reaction (qPCR)}

qPCR was performed using TaqMan ${ }^{\mathrm{TM}}$ Roundup Ready Soya Quantification Kit according to manufacturer instructions. The experiment performed on the Applied Biosystems StepOnePlus Real-time PCR System machine. qPCR Thermal cycle was adjusted under the following conditions: PCR initial activation step at 95 ${ }^{\circ} \mathrm{C}$ for $10 \mathrm{~min}$, followed by 50 cycles of $95^{\circ} \mathrm{C}$ for $15 \mathrm{~s}$, and $60{ }^{\circ} \mathrm{C}$ for $60 \mathrm{~s}$.

\subsection{1. \% RR calculation}

The \%RR value is calculated using the formula (1). From the formula the presentence and the percentage of the Roundup ready soy ${ }^{\mathrm{TM}}$ can be calculated as:

$$
\% R R=\frac{\text { No. of copies of GTS }-40-3-2 \text { target }}{\text { No.copies of lectin target }} * 100
$$

\subsection{Statistical analysis}

The statistical analysis was done using the Microsoft Excel software and the Curve Fitting application of MATLAB MathWorks. Significant difference between each treatment was accepted if $\mathrm{p}<0.05$. Relative expression levels were determined using the $2^{-\Delta \Delta \mathrm{CT}}$ method.

\section{Results}

\subsection{DNA concentration}

Table 2. represents DNA concentration and purity with 260/280 ratio of each sample. 
Table 2. DNA concentration and purity

\begin{tabular}{cccc}
\hline Sample number & Sample & Concentration $(\mathrm{ng} / \mu \mathrm{L})$ & Ratio 260/280 \\
\hline 1 & Soy flakes & 811.85 & 1.901 \\
2 & Breakfast cereal & 975.75 & 2.002 \\
3 & Soy meat 1 & 1584.26 & 1.886 \\
4 & Soy meat 2 & 950.43 & 1.756 \\
5 & Soy flour & 2940.45 & 1.884 \\
6 & Soy cream & 20.78 & 1.809 \\
7 & Soy cappuccino & 15.91 & 1.836 \\
\hline
\end{tabular}

\section{2. qPCR and standard curves}

Fig. 1 and Fig. 2 shows amplification plot for lectin and CP4 gene, respectively, in different samples.
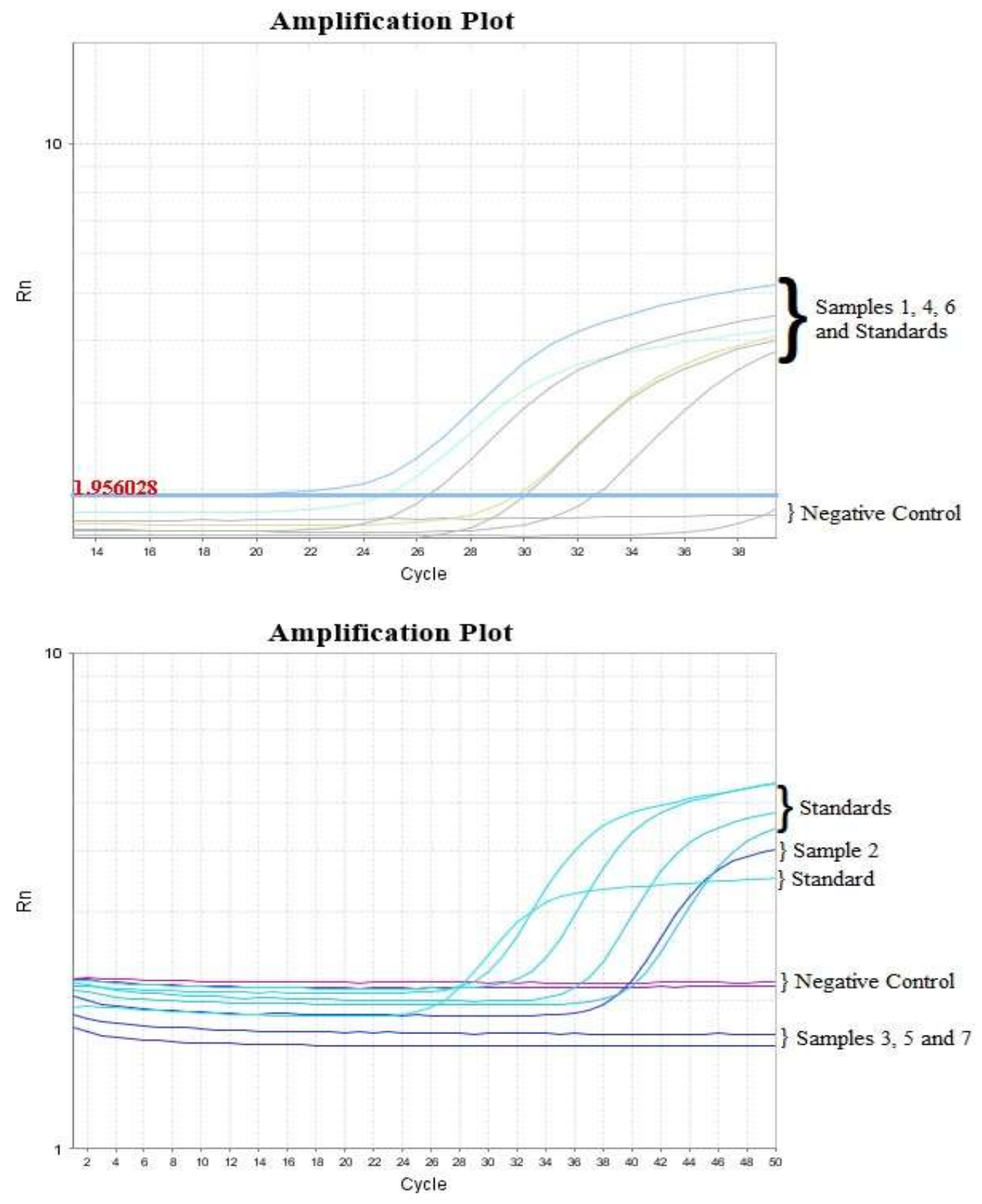

Figure 1. Amplification plot for lectin in different samples 

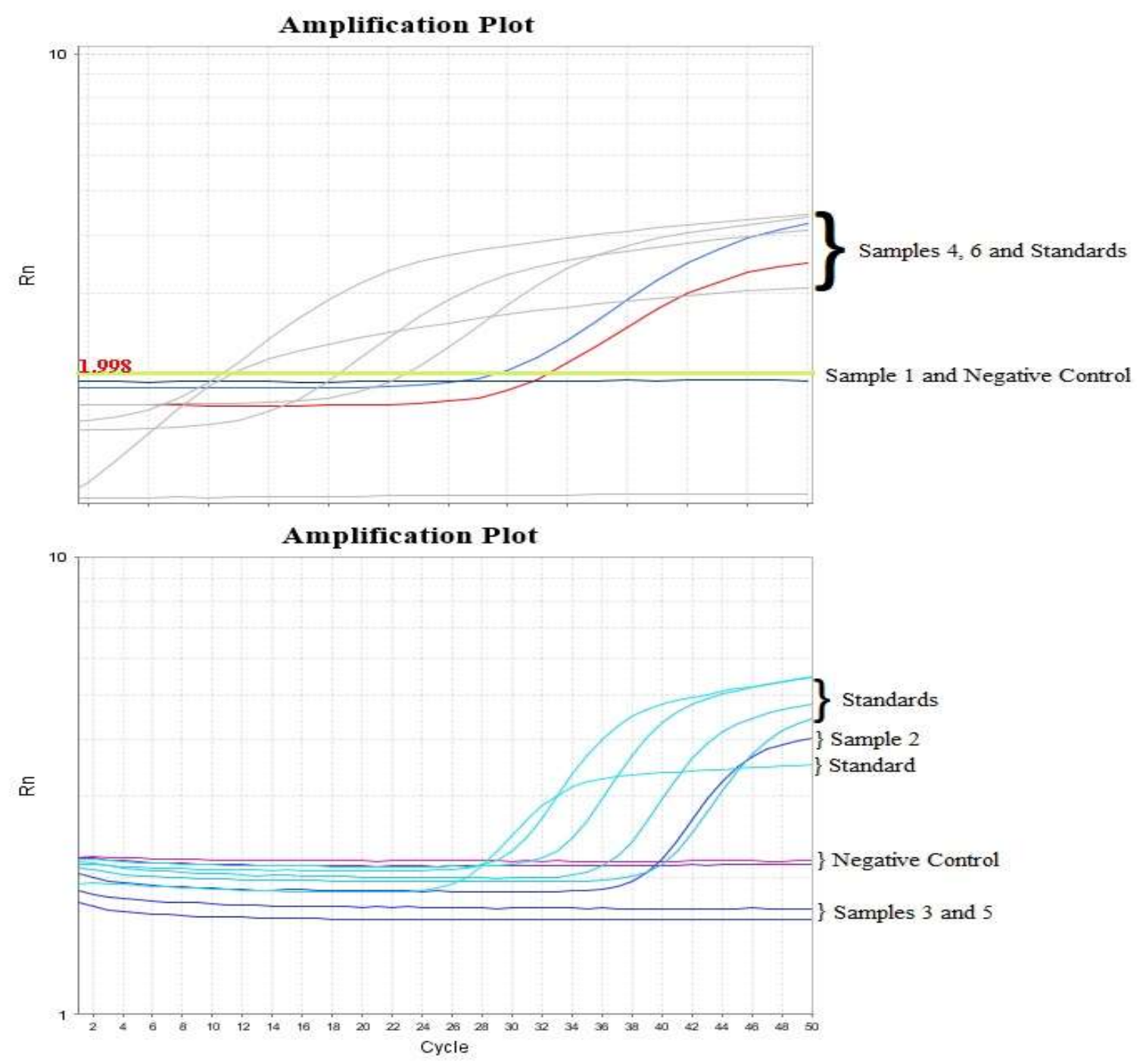

Figure 2. Amplification plot for CP4 gene in different samples
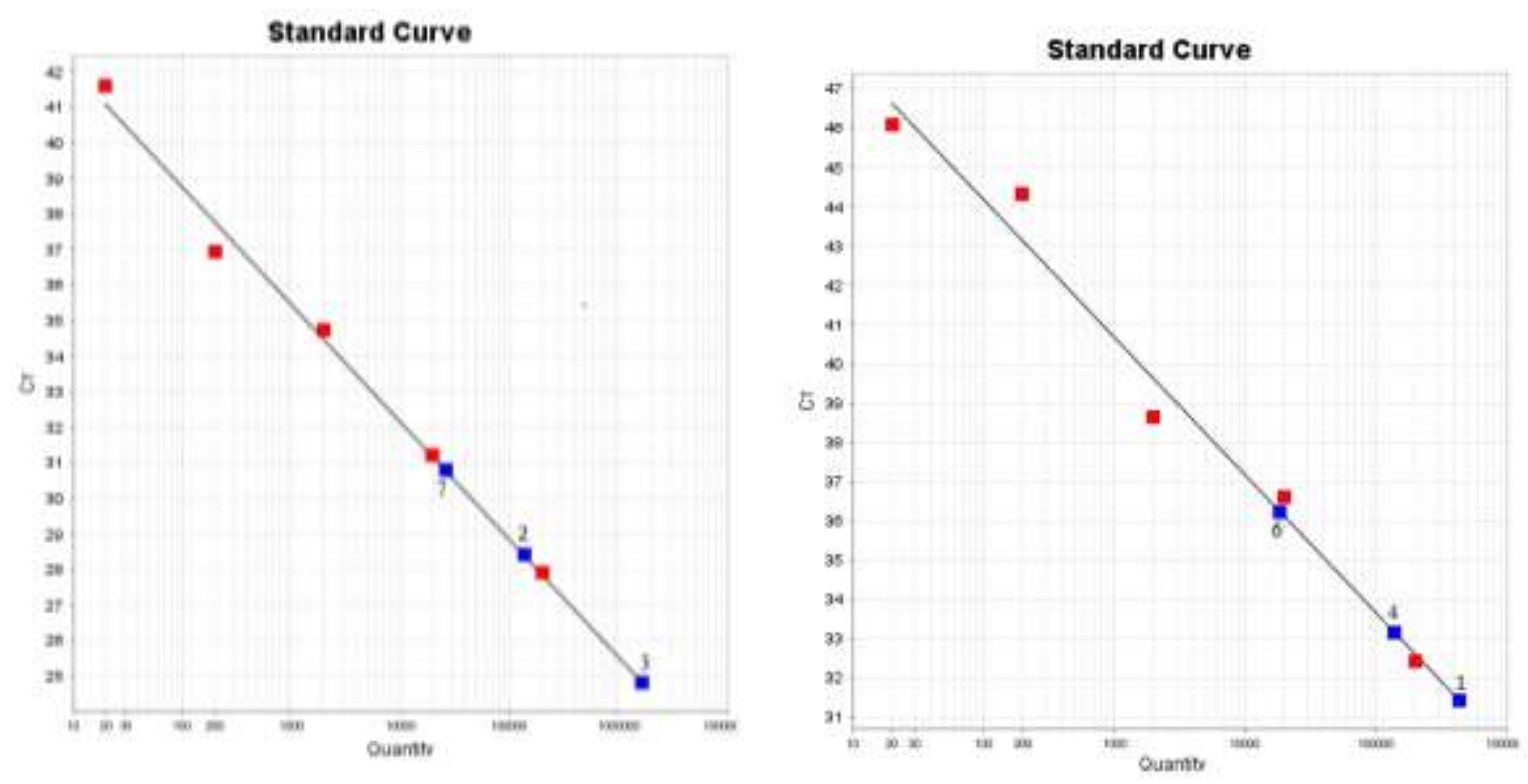

Figure 3. Relative standard curve for lectin gene with samples 1, 2, 3, 4, 6 and 7 

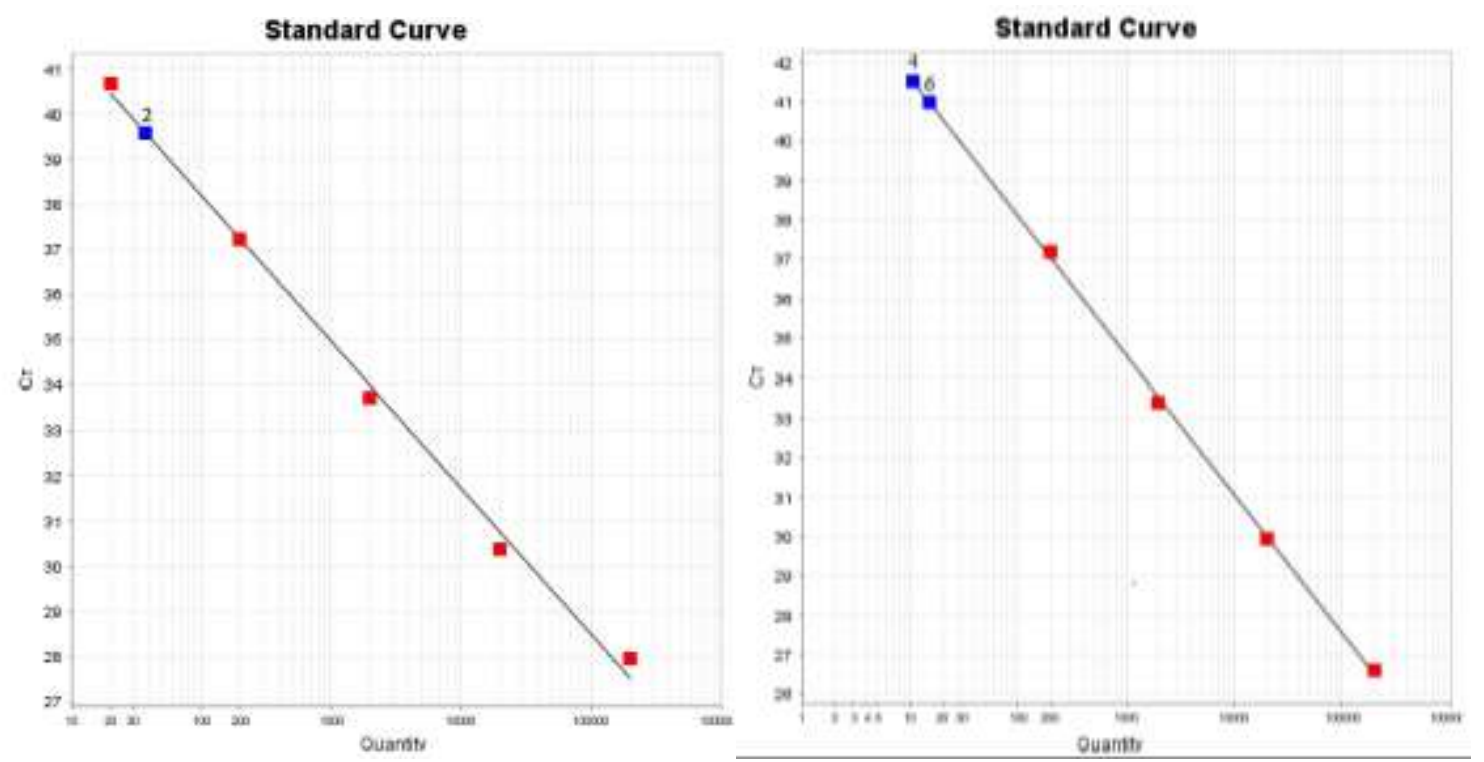

Figure 4. Relative standard curve for cp4 gene with samples 2, 4 and 6

\section{3. $\% R R$ in positive samples}

Bosnian states the limit for GMO is $0.9 \%$, now this value must be compared with calculated values. The step for calculation these values is done with the help of the formula (1).

Table 3. represent the results of $\%$ RR in samples 2, 4 and 6.

Table 3. \%RR in samples 2, 4 and 6

\begin{tabular}{cccc}
\hline Sample & Quantity Lectin & Quantity CP4 & \%RR \\
\hline 2 & 126679.3828 & 37.43021774 & 0.002887 \\
4 & 374906.0625 & 10.82234192 & 0.048633 \\
6 & 31637.93945 & 15.38647556 & 0.029547 \\
\hline
\end{tabular}

\section{Discussion}

The isolated DNA with the seed protocol was quantified and the results are in shown in table 2. It can be concluded that liquid samples have much harder to be treaded and isolated compared to dry samples. Furthermore, for samples that are extremely dry, like flour, it is better to use less material, and for samples like soy meat, it is better to treat it with liquid nitrogen prior to homogenization. The protocol yielded high amount of DNA and had good purity, only soy meat 2 was contaminated with protein, but was pure enough for qPCR analysis.

Samples that were successfully isolated and had an acceptable ratio were tested for the presence of lectin and CP4 gene. Lectin was used to scan the samples for the presence of soy, since lectin is a soy specific gene [11]. If there was no lectin found, it indicates that there is no soy present, and thus, the samples would not be testable for the presence of genetically modified soy. In figure 1, sample 5 (soy flour) did not amplified the lectin gene, meaning that no soy is present in this sample. From figure 1, it can be observed that samples 3,5 and 7, 3 out of 7 (42.86\%) did not amplify, indicating products without soy. The range of Ct-values varies from 23.19 to 29.45 , having an average Ct-value of 25.79. The logarithm concentration is 385705.3. Logarithm concentration refers to the number of copies after amplification. If the logarithm concentration is $n$, the number of copies is $10^{\mathrm{n}}$. From figure 2 it can be observed that samples 1,3 and 5, were positive for the presence of foreign introduced material. Those are soy flakes, soy meat 1 , and soy flour. The Ct-values varies from 39.56 to 41.52 , having the average of 41.52 . The logarithm concentration is 21.21 . 
From standard curves, shown in Fig. 3 and Fig. 4 the correlation between the sample position with the quantity (Ct value) can be made. The focus is on Fig. 4, where the CP4 gene in shown. Sample 2 has the highest quantity of CP4 gene, whose exact number is calculated with the formula (1) and placed in table 3.

As mentioned before, in Bosnia and Herzegovina, the limit for GMO is $0.9 \%$. This value is compared with the results shown in table 3. From table 3 the actual amount was calculated and can be seen there. These results show how the analyzed samples, show specific amount of CP4 percentage, do not need to be labelled as GMO, but as already mentioned above, sample 4 was labelled as GMO free but includes CP4 in its soya genome, being GMO, which is mislabeling the product and false selling. These samples are still in the regulation of the Bosnian and Herzegovinian law, but still higher institutions should take care of these products into consideration and observe the import of the produces. In addition, it is important to emphasize that samples 3, 4 and 6 were labelled as GMO free food, but they may still be a GMO product since not all genes or regulatory elements were tested in this study.

One study conducted in Bosnia and Herzegovina which was testing different products for different specific GM elements, revealed that 19 were positive, while 77 negative for those GM elements [12]. Another study which was also conducted in Bosnia and Herzegovina for soybean and maize products, and which was labeled as "GMO free" has detected positive signal for GMO. Ct-values (Ct > 38) were high in all reactions that indicated target concentrations approaching LOD of the method. It was concluded that label "GMO free" is not untrue, but that it should be applied correctly and treated with more carefully [13].

A study conducted in Turkey, where GMO containing foods are not allowed, 9 samples were examined (flour, chop meat, meat, sprout 1 , sprout 2, coffee, cream, milk, and tofu). It was shown that all samples contained lectin, i.e., soybean. Furthermore, when the samples were tested for EPSPS (GMO presence), it was found out that $100 \%$ samples, contained below 0.1 of the enzyme [7]. Another study conducted in Turkey examined 10 samples (maize flour, canned maize, soy flour and beans, bread and bread mix, infant formula, cake and biscuits, dehydrated soup, meat products, soy sprout, soy milk, soy sauce, maize kernels, and maize starch) in the total number of 100 products. It was discovered that $25 \%$ of all the products screen were positive for GMO (32.6\% of tested maize sample, and $19.3 \%$ of tested soy samples). None of GMO products had label on them [14].

\section{Conclusion}

The results have shown that there are soy products in Bosnian and Herzegovinian market, labeled as GMO free, but containing the CP4 gene, an indicator of GM soy. To examine how much of GMO food is being imported, a wider and bigger study, including more GMO indicator genes, should be done on certain soy products sold in Bosnian and Herzegovinian market.

\section{References}

[1] NCBI, "Plants, Genetically Modified," 2002. https://www.ncbi.nlm.nih.gov/mesh?Db=mesh\&Cmd=DetailsSearch\&Term=\%22Plants,+Genetically+ Modified\%22\%5BMeSH+Terms\%5D.

[2] S. Key, J. K. C. Ma, and P. M. W. Drake, "Genetically modified plants and human health," J. R. Soc. Med., vol. 101, no. 6, pp. 290-298, 2008, doi: 10.1258/jrsm.2008.070372.

[3] E. Commission, “GMO legislation,” 2001. https://ec.europa.eu/food/plant/gmo/legislation_en.

[4] "Law of genetically modified organisms," “'Službeni glasnik BiH”, , no 23/09, 2009.

[5] J. Clive, "Global Status of Commercialized Biotech/GM Crops: 2014," ISAAA Br., vol. 49.

[6] E. W. Lusas and M. N. Riaz, "Overview of Soybean Processing and Products Soy Protein Products: Processing and use," J. Nutr., vol. 125, pp. 573S-580S, 1995.

[7] M. Mandaci, Ö. Ćakir, N. Turgut-Kara, S. Meriç, Ş. Ari, and Ş. Ari, "Detection of genetically modified 
organisms in soy products sold in turkish market," Food Sci. Technol., vol. 34, no. 4, pp. 717-722, 2015, doi: 10.1590/1678-457X.6441.

[8] T. Funke, H. Han, M. L. Healy-Fried, M. Fischer, and E. Schönbrunn, "Molecular basis for the herbicide resistance of Roundup Ready crops," Proc. Natl. Acad. Sci. U. S. A., vol. 103, no. 35, pp. 13010-13015, 2006, doi: 10.1073/pnas.0603638103.

[9] H. Wu et al., "Presence of CP4-EPSPS component in Roundup Ready soybean-derived food products," Int. J. Mol. Sci., vol. 13, no. 2, pp. 1919-1932, 2012, doi: 10.3390/ijms13021919.

[10] ISAAA, “Global status of Commercialized biotech/GM Crops: 2016," Isaaa Br., no. 52, p. 127, 2016.

[11] M. J. Chrispeels and N. V. Raikhel, "Lectins, lectin genes, and their role in plant defense," Plant Cell, vol. 3, no. 1, pp. 1-9, 1991, doi: 10.1105/tpc.3.1.1.

[12] V. Turkulja, J. . Salapura, D. . Jošić, B. Ćurković, J. Vasić, and G. Babić, "Testing for the presence of genetically modified living plants, plant parts and plant products in the entity of Republic of Srpska (Bosnia and Herzegovina) in 2015," in VII International Scientific Agriculture Symposium," Agrosym 2016", 2016, pp. 1616-1620.

[13] A. Durmić-Pašić, A. Ahatović, and E. Al-Momani, "Screeing for GMO in " "GMO free" labelled products," in Proceedings of the 24th International Scientific-Expert-Conference of Agriculture and Food Industry, 2013, pp. 285-288.

[14] Ö. Özgen Arun, F. Yilmaz, and K. Muratoĝlu, "PCR detection of genetically modified maize and soy in mildly and highly processed foods," Food Control, vol. 32, no. 2, pp. 525-531, 2013, doi: 10.1016/j.foodcont.2013.01.023. 